\title{
Emociones, agravio y reconocimiento: los lesionados del 22 de Abril de 1992 en Guadalajara, México
}

\author{
Jorge Federico Eufracio Jaramillo \\ Instituto Tecnológico y de Estudios Superiores de Occidente, Guadalajara, México. \\ Email: jorgeeufracio@iteso.mx
}

Resumen: El presente artículo pretende aportar a los debates sobre el papel de las emociones en la acción colectiva. Para ello, se establecieron tres ejes teórico-conceptuales que lo articulan: 1) la sociología y antropología de las emociones; 2) la injusticia y el agravio moral y; 3) las luchas por el reconocimiento. En concreto, el documento tiene el objetivo de explicar las prácticas y sentires de un grupo de lesionados en Guadalajara, México, que fueron víctimas de una catástrofe antropogénica. La información utilizada para ello proviene de la revisión de notas periodísticas, la realización de entrevista y de una inmersión etnográfica de algunos años. Lo propuesto es que su acción colectiva sólo puede ser comprendida, en términos de su génesis, fuerza, objetivos y duración, por la profundidad del daño sentido, así como en las resultantes emociones morales.

Palabras clave: Dolor; tragedia; movimientos sociales; indignación; represión.

\section{Emotions, grievance and recognition: the injured of April 22, 1992 in Guadalajara, Mexico}

\begin{abstract}
This article aims at feeding the debates on the role of emotions in collective action. To this end, three theoretical-conceptual frameworks were established to articulate it: 1) the sociology and anthropology of emotions; 2) injustice and moral offense; and 3) struggles for recognition. Concretely, the document aims at explaining the practices and feelings of a group of injured people in Guadalajara, Mexico, who were victims of an anthropogenic catastrophe. The information used for this purpose comes from the review of journalistic notes, the conduct of interviews and an ethnographic immersion conducted over some years. The proposal is that their collective action can only be understood, in terms of its genesis, strength, objectives and duration, by the depth of the damage felt, as well as the resulting moral emotions.
\end{abstract}

Keywords: Pain, tragedy; social movements; indignation; repression.

\section{Emoções, injúria e reconhecimento: os feridos de 22 de abril de 1992 em Guadalajara, México}

Resumo: Este artigo pretende contribuir para os debates sobre a importância das emoções para a ação coletiva. Para isso, foram estabelecidos três eixos teórico-conceituais que o articulam: 1) a sociologia e a antropologia das emoções; 2) a injustiça e a injúria moral e: 3) lutas pelo reconhecimento. Especificamente, o documento visa explicar as práticas e sentimentos de um grupo de pessoas feridas em Guadalajara, no México, que foram vítimas de uma catástrofe antropogênica. A informação usada para isso vem da revisão de notas jornalísticas, da realização de entrevistas e de uma imersão etnográfica de alguns anos. A proposta é que sua ação coletiva só pode ser entendida, em termos da sua gênese, força, objetivos e duração, pela profundidade do dano sentido, bem como pelas emoções morais resultantes.

Palavras chave: Dor; tragédia; movimentos sociais; indignação; repressão. 


\section{Introducción: un necesario contexto de la tragedia}

El 22 de abril de 1992 la ciudad de Guadalajara, la más poblada del occidente de México y la segunda a nivel nacional, fue escenario de un desastre que la cambió para siempre. Ese día varios kilómetros del colector profundo explotaron dejando tras de sí un sinfín de daños materiales, así como centenares de muertos y heridos. La ciudad jamás había presenciado una situación de tal magnitud, por lo cual las autoridades se vieron de inmediato rebasadas.

Al respecto, varios días antes de la catástrofe, los vecinos del tradicional Sector Reforma ya habían denunciado fuertes olores a hidrocarburos. Las instituciones del Estado (entiéndase gobierno municipal de Guadalajara y gobierno del estado de Jalisco principalmente) poco sabían sobre este tipo de situaciones por lo que se dedicaron, la noche anterior al siniestro, a lavar con agua los drenajes y a observar la oscilación de los explosímetros, pero sin entender el problema de fondo. Después de las explosiones las hipótesis indicaban a una probable responsabilidad causal de la empresa paraestatal Petróleos de México (PEMEX), ya que era la única que manejaba los hidrocarburos que habían ocasionado aquella tragedia.

Sobre las consecuencias surgieron diversas voces. Eran las de los vecinos que perdieron sus casas, los trabajadores que tuvieron que abandonar sus fuentes de trabajo, los pequeños y medianos empresarios que vieron sus negocios estropeados. Todos ellos exigieron al gobierno, vía la protesta y la organización social, un castigo ejemplar para los culpables y la reparación de los daños. Sin embargo, hubo unas voces que no se sumarían en un principio: las de las docenas o cientos de lesionados que se encontraban dispersos en todos los hospitales de la ciudad con sus heridas sangrantes o luchando por sus vidas. Para ellos pasarían meses antes de que pudieran regresar a sus casas. Además, no serían los mismos jamás pues la falta de una pierna, de un brazo, de la vista etc. dejaría secuelas físicas, sicológicas y morales que serían permanentes. A lo anterior se sumaría la inoperancia e insensibilidad del Estado mexicano para brindarles las necesarias atenciones (en términos de servicios de salud integrales y pensiones por discapacidad). Ante esto, un pequeño grupo de ellos (aquellos que lograron organizarse) decidieron constituir un colectivo, la Asociación 22 de Abril en Guadalajara, que tendría el objetivo de exigir respuestas contundentes a las secuelas.

Así, este artículo tiene por objetivo general exponer la lucha de estos lesionados por los últimos 27 años, evidenciando principalmente el papel que han jugado las emociones negativas en la búsqueda de soluciones por parte de las instituciones gubernamentales (mediante las peticiones formales, las negociaciones y/o las movilizaciones). En este sentido, han sido innumerables las situaciones en las cuales el Estado, utilizando diferentes estrategias, los ha coaccionado para disolver sus actos de protesta o para dividir a su colectivo. Así, las emociones negativas no sólo refieren a la existencia de una sensación desagradable sino también a una construcción social basada en el dolor y daño causados por la desigualdad, las jerarquías y la invisibilización. Debido a lo anterior, las emociones serán vistas como un mecanismo que ha actuado en dos vías: a) como una energía que les ha permitido enfrentar la insensibilidad, y la represión y b) como una fuerza vital que ha impulsado la sinergia entre estas personas vía la resignificación de su lucha en términos de dignidad, justicia y solidaridad.

\section{Bases analíticas centrales y marco conceptual}

Para cumplir tal meta, el artículo está construido a partir de tres diálogos: 1) los campos de la antropología y la sociología que enlazaremos para entender, en nuestro caso, cómo se relacionan las emociones de los sujetos con la acción colectiva; 2) la vinculación entre emociones, injusticia y agravio moral y; 3) el diálogo complementario entre las identidades colectivas y las luchas por el reconocimiento, ya que sólo la comprensión proveída por este enmarque analítico nos permitirá, desde nuestra perspectiva, explicar los sentidos otorgados a la acción colectiva de los lesionados, las bases de su identidad grupal y la profundidad de sus metas.

Tanto la antropología como la sociología han encontrado en las emociones un campo sumamente fértil de estudio. Al respecto, si bien es cierto que cada una de estas disciplinas ha construido conocimiento diferenciado sobre dicho campo, también lo es que sus interrelaciones son más que claras. Para el objeto de estudio que nos compete, hemos emparentado ambas ramas a partir de los siguientes debates. Iniciando por la antropología de 
las emociones consideramos que, además del trabajo de campo centrado en el actor social (en el cual abundaremos en la sección metodológica), es sumamente importante partir de la discusión entre dos posturas dominantes: naturalista-universalista y culturalista-construccionista (Bourdin, 2016, p. 56). La primera sostiene que las emociones son expresiones fisiológicas, nacidas en el cuerpo y determinadas evolutivamente (Breton, 2013, p. 70), mientras la segunda afirma que, por el contrario, las emociones varían de acuerdo a cada contexto cultural. Así la antropología, en consideración de la última perspectiva, se ha orientado a explicar las emociones a partir de aquellas normas y reglas (sociales) que llevan a sentir, pensar, reaccionar y actuar (Jacobo, 2016, p. 376). Por lo tanto, las emociones, al estar culturalmente supeditadas, están cargadas de significados. Sin embargo, una de las principales críticas es que el condicionamiento cultural no se traduce en determinación de las experiencias emocionales, por lo que existen otros elementos que interfieren en dichas experiencias como las bases biológicas y físicas, así como las estructuras sociales y las relaciones de poder que no suelen ser tomadas en cuenta por los análisis antropológicos de este corte.

Siguiendo estos debates y críticas buscamos incorporar a nuestro análisis de las emociones la variable corporal. Lo anterior porque, como lesionados físicos, los miembros de la Asociación 22 de Abril experimentan diversas emociones que no pueden ser comprendidas sin la observación de dicha variable. En este sentido, propondremos dos ejes de análisis acerca del cuerpo: 1) La clasificación de emociones de Jasper (2013). En su modelo plantea, como punto inicial, una relación entre ciertas sensaciones físicas (definidas como pulsiones) y un conjunto de emociones básicas. Partiendo de ello, formularemos el concepto de shock físico (entendido como un hecho catastrófico que provoca lesiones físicas serias o discapacidades permanentes) para enmarcar la profundidad de las secuelas corporales y, en diálogo con Jasper, evidenciar el grado de alteración de la vida cotidiana, así como las emociones que esto genera entre los lesionados y 2) el concepto de dolor. Siguiendo a Francis (2007), Leavitt (1996) y Bendelow y Williams (1998), autores que han orientado sus esfuerzos hacia la comprensión del vínculo entre emociones, salud y cuerpo, analizaremos el dolor en dos vías: como feeling (dolor físicamente sentido) y como meaning (sentido atribuido al dolor), lo cual nos ayudará a comprender las emociones de los lesionados al enmarcarlas tanto en sus consideraciones físicas como culturales.

Es justo a partir de estos dos puntos que deseamos establecer un vínculo entre la antropología y la sociología de las emociones. En efecto, desde nuestra perspectiva la sociología, en especial aquella ramificación que ha teorizado el campo de la acción colectiva, permite entender a las emociones como un motor de la movilización social y/o como formadoras de identidades colectivas (Polleta y Jasper, 2001). Para el caso que nos compete estos dos elementos serán sumamente importantes, pero para profundizar en sus significados es necesario conectarlos con las emociones vividas por los sujetos en tanto lesionados físicos. Por ello argumentaremos, desde ese necesario vínculo entre antropología y sociología, que las emociones provocadas por las injusticias experimentadas son la pieza clave para entender la acción colectiva de los lesionados, pero que las primeras no pueden ser comprendidas en su profundidad sin una reflexión acerca de las secuelas físicas permanentes dejadas por las explosiones.

En definitiva, si nuestra meta teórica es explicar a los lesionados físicos como lesionados morales (en tanto personas olvidadas y/o invisibilizadas) es necesario comprender antropológicamente el significado otorgado a la lesión corporal permanente, cómo esto se vincula a las fuertes emociones morales (concepto utilizado por Jasper para señalar todas aquellas experiencias emocionales de aprobación o rechazo basadas en intuiciones o principios morales) y, finalmente, la relevancia sociológica de éstas para la acción colectiva de los lesionados.

De esta manera, las emociones conectadas a las experiencias de injusticia vividas por los lesionados a lo largo de 27 años, nos llevarán a catalogarlos como agraviados morales. Concepto utilizado por Barrington Moore (1989) para postular que la acción colectiva puede emerger de un sentimiento profundo de indignación, pero especialmente cuando éste se vincula a la falta de cumplimiento de las funciones básicas de protección por parte del Estado. Así, entenderemos estas emociones como negativas pero no sólo como las experiencias de desagrado definidas en el campo de la psicología, sino más bien desde lo que Kemper (2007) propone sociológicamente como la externalización de esas experiencias en formas de conflicto que, además de basarse en poderes desiguales o jerarquías, implican el rompimiento de unas determinadas expectativas (Bericat, 2016, p. 493-494). Para el caso que nos compete, dicho rompimiento se da en la ausencia de resoluciones y/o respuestas 
de las instituciones gubernamentales hacia los lesionados. Son esas emociones negativas el mecanismo sociológico que les permitió no sólo encausar sus movilizaciones y demandas, sino también definir claramente a que o a quiénes dirigirlas, por lo que lo «negativo» funciona como el motor que direcciona la acción. Este direccionamiento emocional y práctico Gamson (1992) lo engloba, como lo veremos en el cuerpo del artículo, en el concepto de marco de injusticia.

Por otra parte, postularemos que es justo esa condición de agravio moral lo que ha permitido no sólo la sobrevivencia de la asociación y de sus acciones colectivas, sino también la formación de una identidad grupal basada en el dolor compartido. En este sentido, comprenderemos ese vínculo como un fortalecimiento de los compromisos morales y de la solidaridad (considerado por Jasper como la creación de un we-ness), pero a la vez como resultado de un proceso de aprendizaje emocional, de trabajo emocional utilizando el concepto de Hochschild (1979) en términos del manejo contextual de las emociones en la acción colectiva, que los han llevado a saberse conducir frente a las instituciones gubernamentales y los funcionarios, así como a dirigir sus protestas o enfrentar los hechos represivos perpetrados por el Estado.

Finalmente, propondremos que, para entender la profundidad de las heridas morales de los lesionados y, por ello, la fuerza que los moviliza, es necesario relacionarlas al concepto de luchas por el reconocimiento (Honneth, 2009) el cual pretende, al tratar de explicar sociológicamente el sufrimiento y dolor humanos, una crítica a la sociedad moderna en términos de las reproducción de formas estructurales de menosprecio. Éstas invisibilizan a las personas, razón por la cual requieren luchar para no ser olvidadas. En el caso que nos compete, deseamos especificar que los lesionados luchan por ser reconocidos como los portadores de una herida abierta, de una laceración moral que ha revelado en estos 27 años no sólo el abandono gubernamental, sino también la falta de solidaridad en una sociedad que tiende a normalizar las desigualdades, la violencia y las injusticias.

\section{Metodología}

La mayor parte de la información empírica utilizada fue recabada por medio de revisiones de archivo, entrevistas a profundidad con los lesionados y, especialmente, de una amplia estrategia etnográfica. La primera refiere a una exploración realizada al archivo de la Asociación, el cual contiene un sinnúmero de notas periodísticas, oficios y fotografías que resumen los 27 años de luchas de los lesionados. Respecto a las entrevistas, éstas han consistido en la recolección de los testimonios de por lo menos 20 de los lesionados (de un total de 60), el objetivo de éstos no sólo ha sido el de conocer lo que les pasó aquel trágico día, sino también cómo inició la lucha y lo que ha significado para ellos. Por su parte la etnografía se ha basado en una participación directa dentro de varias de las actividades de los lesionados y que han ido desde la entrega de oficios y negociaciones directas con funcionarios hasta las movilizaciones y protestas. Es justo esta inmersión la que nos ha permitido entender la importancia de las emociones para la acción colectiva de estas personas e incluso llegar a compartirlas con ellos ante diferentes hechos que les han provocado indignación. Sin embargo, ha sido ese mismo ejercicio etnográfico el que nos ha permitido ingresar a su cotidianidad (conocer sus casas y a sus familias), lo cual nos ha llevado a entender la extensión y simultaneidad de las lesiones físicas, sicológicas y morales. Para nosotros, ese conocimiento no podría haber sido alcanzado si sólo nos hubiéramos centrado en los actos de protesta o en las movilizaciones públicas, pues eso hubiera dejado de lado todas aquellas afectaciones que son parte del día a día de estas personas y de quienes los rodean. Sin esta pieza no sería posible explicar el significado de la lesión física, la profundidad del agravio moral, las motivaciones esenciales de su acción colectiva y los sentidos imputados.

\section{Los sobrevivientes del 22 de Abril: de las pulsiones inmediatas de la lesión física a la emoción moral}

Según la tipología básica de emociones propuesta por Jasper (2013), existen una serie de impulsos corporales fuertes o pulsiones que son difíciles de ignorar (como la necesidad de dormir) y que pueden encarnar diversos sentimientos. Proponemos que éstas pueden vincularse a fuertes emociones negativas cuando su manejo habitual es alterado profundamente por lo que llamaremos un shock físico. Es decir, un evento catastró- 
fico (como el ocurrido el 22 de abril de 1992) que deja huellas, heridas y/o discapacidades corporales permanentes. Lo que planteamos concretamente es que, las funciones fisiológicas básicas (orinar, defecar, dormir, comer etc.) y las sensaciones tales como el cansancio, conllevan un proceso de aprendizaje que permiten naturalizarlos y volverlos partes conformantes de la cotidianeidad, pero que el acaecimiento de un shock físico que desestructura esa conducción habitual, además del sufrimiento causado por el padecimiento específico, obliga a un nuevo proceso de aprendizaje que sin lugar a dudas genera diferentes emociones.

Este reaprendizaje entre los lesionados del 22 de abril fue particularmente profundo y doloroso. Por ejemplo Lilia Ruiz Chávez, la actual presidenta de la Asociación 22 de Abril en Guadalajara A. C., sufrió la amputación de su pierna izquierda, por lo que tuvo que reaprender a sentarse y a utilizar un baño ya que la falta de su extremidad la llevaba a marearse constantemente. José Antonio Vargas, a sus escasos 15 años, quedó inmovilizado de la cintura para abajo durante las explosiones, por lo que ha requerido de una silla de ruedas para moverse, además de una recomprensión completa de su cuerpo para manejar pulsiones que, ante la falta de sensibilidad en una parte considerable de su estructura corporal, fueron ampliamente modificadas. Luis Cruz Franco sufrió de estallamiento de vísceras, fractura de pelvis y de una disección de la uretra que le impidieron no sólo el desempeño de algunos movimientos corporales, sino también el manejo de algunas necesidades fisiológicas sin asistencia. Finalmente, son muchos los lesionados que señalan la imposibilidad de dormir como lo hacían antes de las explosiones, ya que algunas de las huellas permanentes más comunes entre ellos residen en la columna vertebral. Esto les impide estar acostados mucho tiempo o permanecer en una sola posición. Todos ellos llevan barras de Luque que los habilita a sentarse, ponerse de pie y caminar.

Por supuesto que cada caso representa un reaprendizaje distinto de acuerdo a la profundidad o gravedad de las lesiones físicas, las cualidades individuales, el apoyo de la familia y una serie de variables (económicas, sociales etc.) que influyen. Sin embargo, lo central es que, en todos los casos, la lesión vinculada al shock físico significó una amplia modificación de su vida cotidiana comenzando, para muchos de ellos, en el manejo de las mencionadas pulsiones y a su vez en la imposibilidad o suma dificultad para realizar otras actividades rutinarias. Así, por ejemplo, el shock físico se tradujo en que muchos de ellos no pudieran regresar a laborar (en algunos casos las lesiones les impidieron ejercer las actividades físicas que eran necesarias para cumplir con su trabajo. En otros la discapacidad resultante provocó que los empleadores no quisieran contratarlos), ejecutar las faenas básicas del hogar (tan cotidianas como barrer, trapear, hacer de comer, lavar etc.) e incluso, en el caso de algunas de las mujeres lesionadas que durante las explosiones resultaron dañadas de la espalda, darles de comer a su bebés debido al esfuerzo que implicaba cargarlos y mantenerse en la posición de lactancia. Por otra parte, a estas situaciones hay que sumar el efecto creado por el shock físico en los familiares de los lesionados ya que, además de la impresión sicológica del evento, algunos de ellos tuvieron que encargarse de su atención: llevarlos a sus consultas médicas, trabajar para mantener al resto de la familia (cuando el lesionado era el responsable del sustento) e incluso buscar apoyos y resoluciones por parte de las instituciones del Estado.

Por lo anterior consideramos que la alteración de lo cotidiano entre los lesionados fue intensa. El shock físico logró dañar el conjunto de prácticas y actividades simbólicas que condicionaba y reacondicionaba sus vidas (Lalive, 2008, p. 20), que le daba significado al transcurrir diario y a sus rutinas. En otras palabras, rompió el flujo de la cotidianidad que les permitía construir certezas, generando así un estado de incertidumbre e inseguridad. Siguiendo este argumento, el sufrimiento ocasionado por esta compleja situación debe ser situado en un entramado en el que se intersectan lo estructural, lo social, lo interpersonal, lo sicológico y lo físico (Francis, 2007, p. 591). Esto desencadenó entre los lesionados diversos estados de ánimo. Para Jasper, dichos estados refieren a etapas que pueden perdurar en el tiempo, pero que se diferencian de las emociones por carecer de un objeto directo (Jasper, 2014, p. 48), es decir, no tienen un rostro o entidad claros al cual dirigirlos.

Por ejemplo, Lilia Ruiz menciona que toda esta dolorosa experiencia le significó pasar por etapas de coraje, autocompasión y vergüenza. Cada una de ellas le llevaron «años, días y horas interminables» (Eufracio, 2017, p. 99). En concreto recuerda dos estados de ánimo que marcaron esa primera fase después del shock físico: 1) sentía una enorme vergüenza de que las personas la vieran en la calle pues se sentía incompleta. No le gustaba que nadie la viera sin una pierna; 2) experimentó mucho enojo hacia todos, pero en especial cuando las personas pretendían brindarle palabras de aliento. Entre los testimonios de los lesionados este estado de ánimo se presentó de manera muy recurrente, a decir, una gran molestia «hacia el mundo». 
Así para los lesionados esta fue una etapa muy dura de comprensión de lo que les había pasado, pero también de lo que podría sobrevenir para ellos en un futuro inmediato. Por un lado, se dieron cuenta por diversos medios que no eran los únicos; existían otros como ellos que habían sufrido no sólo las lesiones físicas y sicológicas de las explosiones, sino también la insensibilidad y desconsideración institucional. Esto porque los apoyos para ellos fueron inadecuados (montos de dinero que no alcanzaron ni para pagar las especialidades médicas o las primeras prótesis) y limitados (la indemnización monetaria se entregaba, pero después de firmar un documento en el cual se liberaba al Estado mexicano de cualquier responsabilidad futura). Por otro lado, comenzaron a entender que su lucha grupal no sería, en lo primordial, para que el Estado investigara a fondo la responsabilidad en los hechos (qué y/o quiénes habían provocado la tragedia), sino más bien para que aceptara lo que Joseph Gusfield (2014) define como responsabilidad política, en este caso, de atender las secuelas dejadas por las explosiones más allá de cualquier imputación causal. Es así como la confluencia de las lesiones físicas, las latentes cicatrices sicológicas y la irresponsabilidad gubernamental se han englobado en una profunda sensación colectiva de injusticia (Gamson, 1992, p. 31) y por lo tanto en una emoción moral (Jasper, 2013, p. 48). Es decir, en un sentimiento de rechazo basado en principios morales que, en este caso, refiere a la indignación provocada por el rompimiento de un compromiso fundamental entre el Estado y los lesionados del 22 de Abril.

\section{El redimensionamiento del dolor: injusticia, agravio moral y el inicio de la acción colectiva}

Cuando Jasper construyó su clasificación de emociones parece decantarse por una ordenación graduada de las mismas. Sobre este punto, argumenta que en la política las emociones reflejas evolucionan en estados de ánimo, que éstos en lo progresivo generan lealtades afectivas y sólo ocasionalmente emociones morales (Jasper, 2013, p. 55). No obstante, proponemos que para entender lo que ocurre con los lesionados del 22 de Abril es imperativo reconocer la simultaneidad (emotiva) que implica el daño físico, el quebranto sicológico y la herida moral provocada por la injusticia. En efecto, en este caso en particular las huellas corporales de la tragedia son permanentes por lo que constantemente «dialogan», se vinculan o interactúan con los estados de ánimo y la emoción moral. De ahí que hayamos querido partir por el shock físico, para transitar por lo sicológico y entender en lo sucesivo el sentido dado a la injusticia en términos morales, pero como un orden lógico/analítico no jerárquico. La afirmación de esta postura teórica tiene que ver, por un lado, con la imposibilidad de comprender a los lesionados (sus prácticas y sus sentires) sin la observancia de la apelación habitual del daño físico pero también, por otro lado, con un vacío teórico/epistemológico que ha llevado, en aras de la explicación cultural, a infravalorar el cuerpo como variable explicativa. En efecto, uno de los principales debates acerca de las emociones descansa en su separación, en ocasiones radical y acrítica, como fenómeno culturalmente determinado o como manifestación física. Desde nuestra perspectiva, las emociones no pueden ser colocadas en un sólo costado de esta dicotomía, sino dentro de un diálogo indisoluble entre ambos: feeling y meaning (Leavitt, 1996, p. 515-518). En otras palabras: sentir como feeling (sensación corporalmente manifiesta) y sentir como meaning (significado imputado). Siguiendo tal propuesta, planteamos que lo ocurrido a los lesionados del 22 de Abril debe ser comprendido como una experiencia de dolor en ambos niveles (Bendelow y Williams, 1998): dolor sentido (por la innegable sensación dejada por las heridas corporales) y sentido del dolor (por la incertidumbre que los llevó a buscar el significado de sus síntomas y, por ende, a preguntarse ¿¿or qué a mí?). Así, en una primera etapa, este dolor había sido encapsulado en la vivencia individual, guardado en la esfera privada (Bendelow y Williams, 1995, p.157) con la finalidad de ser ocultado de las demás personas. Lilia Ruiz nos da un ejemplo muy claro de esto en sus testimonios:

«Se lleva años cada etapa [sicológica], pero tuve que superarlas por mis hijos que estaban chicos. No quería que me vieran acabada. Yo lloraba cuando ellos no estaban, cuando iban a la escuela, o simplemente cerraba la puerta de mi cuarto para llorar. No quería que ninguno de ellos me viera triste. Creo que aún tengo mucho llanto atorado...» (Eufracio, 2017, p. 99).

No obstante, esta forma de manejo del dolor entre los lesionados cambió sustancialmente cuando adquirió dimensiones colectivas. En efecto, cuando la asociación fue creada y pudieron darse cuenta de las enormes similitudes en el trato recibido por parte de las instituciones del Estado, todo cambió. Es en esa etapa que los 
lesionados se percataron, en definitiva, que sus estados de ánimo y su sentido de dolor, ya no podían ser explicados como resultado de la mala suerte, del haber estado en el lugar y en el momento menos indicados o de una obra de dios que aún no cobraba sentido, sino más bien como consecuencia de una negligencia, en un primer momento, y de una postura irresponsable e insensible de los diferentes gobiernos en lo sucesivo.

Es justo ese entendimiento lo que permitió darle forma al oponente; ya había alguien a quien culpar (Jasper, 1998, p. 410) o responsabilizar: «el gobierno». Pero también esa nueva racionalización de la situación, ahora dentro de una trama grupal, provocó una transformación emocional (Collins, 2001, p. 29), es decir, una interconexión que redimensionó lo vivido individualmente para convertirlo en energía movilizadora a partir de un sentimiento de injusticia definido colectivamente (Reger, 2004, p. 206). Este proceso puede ser entendido como un estado muy emocional o hot cognition (Gamson, 1992, p. 32), el cual ya no representaría una simple evaluación abstracta acerca de lo que es equitativo, sino todo un marco de injusticia (Gamson, 1992, p. 32) que canalizaría la indignación. En concreto dicho marco le brindaría direccionalidad (en términos de la definición de un opositor) y objetivos específicos a la naciente asociación.

Ahora bien, ese marco de injusticia cobra su disposición emocional más clara cuando el sujeto productor de la indignación no es un solo individuo, sino más bien una agencia gubernamental o una corporación. Lo anterior porque el dolor infringido, permitido o legitimado por las instituciones (particularmente las del Estado) puede ser estructural, es decir, permanecer en el tiempo en tanto el recambio de agentes puede no alterar, por lo menos de manera contundente, la continuidad de la lesión moral. Además, y quizá más importante, porque la autoridad legítima (en su ejercicio y en su manifestación institucional) es un conjunto de acuerdos que establecen límites y obligaciones entre gobernantes y gobernados, por lo que su violación conlleva una peculiar y profunda injusticia que se define como agravio moral (Moore, 1989, p. 32).

Este concepto nos permite vincular la emoción moral y el marco de injusticia en tanto daño producido y/ o profundizado por el Estado que lleva a la rabia organizada (Poma y Gravante, 2017, p. 39). Al respecto, el agravio es moral porque, además de contener la básica tensión entre lo correcto y lo incorrecto, lo justo y lo injusto, lo humano y lo inhumano (Moore, 1989, p. 41), éste señala que, bajo el principio de que todos tenemos una idea de las tareas y responsabilidades de las instituciones estatales, el contrato social entre gobernantes y gobernados ha sido quebrantado. Esto ante acciones o inacciones que conllevan un incumplimiento o el fracaso de la autoridad para brindar cuidado y seguridad a las personas. Hugo Guillermo Gómez Soto, uno de los lesionados, ejemplifica este agravio moral:

«El daño moral a mí me afecta mucho por lo que dejas de hacer por los tuyos; te limita. A lo mejor ellos [el gobierno] quieren pagar el daño físico: «¿sabes qué? tu lesión vale tanto» y punto. Pero no termina ahí porque nos cortaron las alas. Ahí es donde veo el daño moral. No te permite ser tú, con lo que naciste, con tus aptitudes, con tus virtudes, con tus defectos. Alguien te cortó las alas y no te permite brindarte a los demás por una negligencia.» (comunicación personal, 29 de mayo de 2018).

Este fragmento de entrevista refleja la compleja articulación de lo físico y lo moral en la experiencia emocional vivida por los lesionados. Sobre esto último, también comprende lo vivido como una forma de agravio, ya que para Hugo y sus compañeros el fracaso de las instituciones del Estado comenzó en una «negligencia», es decir, en una decisión que no fue tomada (la de evacuar a todas las personas dentro de la zona en la que se habían percibido olores a gasolina) y que decantó en la muerte de más de 200 personas (según cifras oficiales). No obstante, tal fracaso se profundizaría con la insensibilidad e indiferencia de los sucesivos gobiernos para tratar con las consecuencias humanas de la tragedia. Esto fue lo que llevó a los lesionados a organizarse para luchar por todo aquello que el Estado había dejado de hacer.

La Asociación 22 de Abril en Guadalajara fue registrada oficialmente como organización civil el 5 de mayo de 1993. La primera tarea de Lilia Ruiz, como potencial lideresa de la agrupación, fue la de convocar a todos los lesionados posibles para que se unieran a los esfuerzos colectivos. Para ello, pegó carteles en diferentes lugares públicos y visitó a personas conocidas para que regaran la voz. Las respuestas fueron múltiples pero no todos los concurrentes se quedaron; unos no creyeron en el potencial de la movilización mientras otros desconfiaron de las intenciones de la asociación. Al final, sólo permanecieron alrededor de 80 personas; hoy en día sólo 
quedan 60. Sin embargo, y más allá de su número, su lucha siempre ha tenido objetivos muy claros. Una claridad producida por esa focalización, viabilidad y trascendencia (Romanos, 2011, p. 92) que permiten las emociones en especial las negativas que son muy poderosas (Jasper, 1998, p. 414).

En concreto, los lesionados han establecido dos principales demandas que han guiado sus movilizaciones y su relación con los diferentes gobiernos: 1) el cuidado integral de su salud (atención médica de por vida, medicamentos, cirugías y aparatos ortopédicos) y 2) una pensión vitalicia (manutención mensual irrestricta y adecuada para cada lesionado). Sobre estos puntos es importante mencionar que, en términos de acción colectiva, la asociación ha buscado la mayor parte del tiempo tener un acercamiento formal con las instituciones del Estado y/o los funcionarios antes de recurrir a las protestas. En otras palabras, aprendieron a manejarse en la burocracia institucional, a redactar oficios, a establecer citas con los funcionarios en turno y, en especial, a dialogar o negociar pero siempre utilizando lo que Bendelow y Williams (1995) llaman narrativas emocionales (discursos que reflejan el significado del dolor para los sujetos y sus efectos físicos, sicológicos y emocionales) para concientizar a los interlocutores o confrontarlos moralmente.

Sobre estos particulares encuentros, existen un sinnúmero de evidencias recolectadas durante las inmersiones etnográficas. Sin embargo, hay una en particular que es sumamente ilustrativa y la cual ocurrió a mediados del año 2018. Durante una reunión con el entonces secretario de salud de Jalisco, Alfonso Petersen Farah, para exigirle el restablecimiento de la entrega de medicamentos para los lesionados, dicho funcionario les pidió a los demandantes que tuvieran «sensibilidad» respecto al ejercicio de dinero que tendría que hacer para cumplir con las peticiones. Ante el uso de tal palabra, Lilia Ruiz presentó una inmediata reacción física (se irguió en su silla de ruedas, mostró una notable expresión facial de enojo y miro fijamente a Petersen Farah) y le respondió con suma indignación: «¿sensibilidad doctor? ¿Sensibilidad señor secretario? Es lo que hemos venido a pedir, es lo que hemos pedido por más de 26 años».

No obstante, cuando estas peticiones, negociaciones, entrevistas y narrativas emocionales no cumplen sus objetivos, sobreviene la ruptura de una expectativa moral (Romanos, 2001, p. 97) que lleva a los lesionados a las movilizaciones públicas. Estas protestas van desde manifestaciones con pancartas, la toma de edificios gubernamentales, ruedas de prensa para sancionar moralmente a los organismos ineficientes, plantones permanentes, encadenamientos simbólicos y huelgas de hambre. Todas estas formas de movilización social han estado presentes a lo largo de los años de vida de la asociación, pero su utilización ha dependido de la profundidad del agravio causado por la pasividad institucional (respecto a los problemas específicos en cada etapa) y de la magnitud emocional que se le desea imprimir a cada acción colectiva. Por ello, y como trataremos de mostrar y reafirmar en el siguiente apartado, las específicas prácticas y metas de este grupo no pueden ser entendidas a partir de las concreciones materiales (servicios de salud y pensiones), sino más bien de la trascendencia emocional/moral que les significan, del sentido grupal/identitario que contienen y de la lucha por su reconocimiento social como lesionados del 22 de abril.

\section{Dignidad y vida se recobran con justicia: represión versus identidad y lucha por el reconocimiento del lesionado moral}

Entre los lesionados el agravio moral ha fungido como el principal motor de movilización, pero también como el impulso creador de un espíritu grupal. En efecto, la profundidad de la injusticia vivida y, por ende, de las emociones compartidas, han alentado el fortalecimiento de los vínculos entre los miembros de la asociación y la creación de una identidad colectiva (Poma y Gravante, 2017, p. 39-40). En este sentido, son muchas las acciones colectivas que evidencian esa solidaridad generada entre los lesionados. Sin embargo, son unas cuantas manifestaciones las que representan las historias fundacionales de esa identidad y que, como tales, personifican las creencias y valores compartidos por los participantes (Jasper, 1998, p. 416).

El primer ejemplo fue lo ocurrido a finales del año 2000. Para ese momento, la asociación ya había logrado que el gobierno estatal creara el Fideicomiso de Administración e Inversión de Apoyo de Seguridad Social (FIASS), el cual sería el encargado de proporcionarles las pensiones mensuales. Para su funcionamiento, el órgano determinó que cada fideicomisario recibiera el equivalente a un salario mínimo diario, lo cual representa- 
ba una cantidad muy pequeña. Por ello los lesionados decidieron acudir al Congreso de Jalisco para solicitar el aumento a tres salarios mínimos, pero el Ejecutivo estatal decidió vetar la iniciativa. Dicha acción provocó tal agravio entre los lesionados que decidieron irrumpir en una sesión legislativa, tomar la tribuna y no moverse de ahí hasta que recibieran una respuesta favorable. Al final, después de varios días de plantón y de huelga de hambre, esa manifestación obligó al entonces gobernador, Alberto Cárdenas Jiménez, a recular y a autorizar el aumento en las pensiones. Sin embargo, esa primera gran protesta, en la cual la solidaridad y la fijeza de las metas colectivas se demostraron en el mantenimiento de la protesta, tuvo otras consecuencias posteriores como el inicio del acoso y la represión. En efecto, Lilia Ruiz explica que en esa etapa de la lucha comenzó a sufrir de llamadas telefónicas amenazantes, reportes de vecinos que le informaban sobre el constante paso de personas en motocicleta frente a su casa e incluso la persecución de vehículos por las calles de Guadalajara. Por ello Lilia decidió, ante el miedo, irse todo un año de la ciudad.

Al regresar se dio cuenta que la asociación no había podido avanzar en la consecución de las metas, ya que el gobierno del estado había endurecido su posición hacia ellos y había utilizado el alejamiento de Lilia para socializar, ante los medios de comunicación, que la presidenta de la Asociación 22 de Abril se había ido por «vendida» (Eufracio, 2017, p. 109). Sobre este punto vale la pena mencionar que la represión, entendida como el empleo o amenaza de coerción aplicada por los gobiernos para debilitar la resistencia de los opositores, no siempre refiere a la violencia corporal, sino a toda una variedad de mecanismos subliminales, simbólicos y/o estructurales que conllevan como meta el control social y la normalización de patrones de conducta (González, 2006, p. 5). Así, todos estos dispositivos disuasivos de la acción colectiva deben ser visualizados como formas de coerción que muy constantemente apelan a los activistas en el terreno de lo emocional queriendo infringir miedo, desazón y retraimiento.

No obstante, la respuesta de los lesionados fue la de retomar el camino de la protesta para exponer ya no sólo la falta de respuestas a las demandas, sino también el abuso de la autoridad. Así, Lilia y varios de los lesionados decidieron interrumpir una rueda de prensa en el palacio de gobierno para increpar al entonces secretario general, Fernando Guzmán Pérez Peláez, y señalar que su retiro de la ciudad había sido por el constante hostigamiento recibido por el gobierno (Eufracio, 2017, p. 109). Este tipo de confrontaciones hacia figuras gubernamentales han sucedido en varias ocasiones durante la historia de la asociación, pero sólo en momentos en los que los lesionados han necesitado, ante la acumulación de la desatención, el quebranto de las expectativas colectivas, la insensibilidad y/o la coerción, entrar en un proceso de fuerte descarga emocional (King, 2006, p. 878) que deriva en las protestas y demás sanciones públicas. Todo lo anterior nos lleva a considerar el concepto de trabajo emocional propuesto por Hochschild (1979) para comprender lo que hacen los lesionados en términos del manejo de sus emociones de acuerdo a cada contexto o coyuntura de acción colectiva. Por un lado, esa regulación emocional les ha permitido, en un primer ámbito de diplomacia y negociación, seguir los canales burocráticos para realizar peticiones formales o entrevistarse con los funcionarios. Sin embargo y por otro lado, cuando lo anterior no rinde los frutos esperados ese trabajo emocional se traduce en una herramienta de lucha política (Gravante y Poma, 2018), en un flujo de expresiones frontales que les permiten a los lesionados lidiar con la internalización de la opresión y para sancionar moral y públicamente a las instituciones y a los agentes gubernamentales.

En otro ejemplo de historia fundacional, ésta ocurrida en junio de 2003, los lesionados decidieron realizar una visita a palacio de gobierno con el fin de ser escuchados directamente por el gobernador Francisco Ramírez Acuña. Al respecto Lilia Ruíz expone que, estando ya en las puertas del edificio, los guardias de seguridad intentaron cerrarlas, evitando que la mayoría de ellos ingresara; sólo lo lograron siete mujeres incluida ella. Ante tal acto de rechazo, estas mujeres decidieron quedarse en plantón permanente dentro del edificio. Sin saberlo y sin planearlo, aquello duraría más de un mes. Ahí comerían, dormirían, lavarían su ropa, se bañarían y, además, confrontarían al gobierno de Jalisco. Así, esta protesta debe ser entendida como el resultado de un shock moral, es decir, una reacción emocional a un evento agresivo (Poma y Gravante, 2017, p. 43) infringido en este caso por los agentes del Estado y basado en los siguientes hechos: por principio los guardias de seguridad, al intentar el cierre de puertas con celeridad, prensaron la prótesis de Lilia, lo cual fue sentido por todos los lesionados como un acto insensible y despreciativo. Fue justo esto lo que rencausó la acción colectiva a un episodio de protesta que tuvo como motor la indignación. Emoción que se profundizó con las continuas muestras de hostigamiento y coerción por parte de los agentes policiales como: 1) provocar que éstas mujeres tuvieran el menor contacto 
posible con el exterior; 2) estar físicamente cercanas a ellas para vigilar constantemente lo que hacían, decían o escribían; 3) tirar o manipular su ropa en el patio y 4) confrontarlas discursivamente para demeritar la protesta.

Al final el gobernador nunca les dio la cara. Evitó el contacto con las lesionadas para no tener que escucharlas y atender sus demandas. Sin embargo y más allá de ese intenso agravio moral, el plantón tuvo varias consecuencias que, hasta el día de hoy, tienen una gran trascendencia emocional entre los lesionados. Primero, los actos represivos sufridos no sólo no cumplieron con sus objetivos de disipar el plantón, sino que funcionaron como un fortalecimiento tanto de la unión afectiva/moral (Romanos, 2011 p. 100) como de la identidad colectiva de los asociados. Esto se manifestó, por un lado, en que el resto de lesionados permanecieron a las afueras del palacio en su propio plantón permanente, pero con el objetivo no sólo de dar visibilidad a la protesta hacía el exterior, sino también de estar otorgando toda la ayuda necesaria a quienes permanecieron adentro. Por otro lado, y a la distancia de los hechos, este plantón en particular ha sido significativo, respecto a la construcción de un we-ness (Jasper, 1998, p. 418), para el enraizamiento del sentido de reciprocidad y de compromiso grupal, así como para la profundización de los principios morales colectivos que se perpetúan en los rituales (como las conmemoraciones del 22 de abril) y en las propias historias fundacionales. Lo anterior porque a pesar de las enormes diferencias y separaciones que puede haber entre estas personas afuera de la asociación, al interior todos ellos coinciden en un hecho irrefutable: todos son agraviados morales. Esto los lleva a comprenderse, a indignarse en igual intensidad e incluso a regocijarse, en especial cuando se alcanzan las metas colectivas.

En segunda instancia, este plantón en particular fue sumamente significativo para la creación de empatía entre la sociedad jalisciense y, por ello, para la amplificación de la condena moral de la injusticia. Lilia Ruiz lo explica con sus propias palabras:

«Es el [plantón] más significativo para nosotros porque logramos el mayor apoyo de parte de la ciudadanía. Demostramos la fuerza que teníamos y exhibimos el miedo que el gobierno tenía a enfrentar el problema del 22 de abril. En muchos aspectos creo que rebasamos al gobierno a pesar de nuestras limitaciones. El gobierno se vio muy chiquito ante la grandeza de nuestra lucha, y no lo digo con soberbia, lo digo con verdad, con dignidad. Porque nosotros en cada acto, en cada situación de ese tipo, recuperamos la dignidad. Por eso nuestro lema es «Dignidad y vida se recobran con justicia» ... Creo que nosotros hemos recobrado nuestra dignidad, la justicia no llega, pero la dignidad siempre ha estado de nuestra parte. La justicia no está en nuestras manos, pero la dignidad sí. La dignidad ha superado a la justicia» (comunicación personal, 31 de agosto de 2018).

Así, otra consecuencia manifiesta, fue el orgullo generado por: 1) la exposición y acogimiento colectivo de las emociones y del sentido de agravio infringido por el Estado y 2) la reapropiación del derecho a expresar la rabia y de vencer el miedo (Poma y Gravante, 2017, p. 47). En otras palabras, de convertir la tragedia en una oportunidad colectiva de criticar con fijeza a quienes detentan el poder (Scribano y Artese, 2012, p. 97). Por ello, a su salida del palacio de gobierno fueron recibidas estas mujeres entre cánticos, vítores y muestras de admiración de los estudiantes que desearon enterarse de lo que les pasaba, de los turistas que escucharon sus historias, de las asociaciones civiles que les llevaron comida y agua, de los medios de comunicación que estuvieron siempre pendientes de la actualización de los hechos y, en especial, de sus compañeros, amigos y familiares que nunca las desprotegieron. Fundidos todos en un acto de reconocimiento a la dignidad humana que ha perdurado en la memoria y emociones de los asociados, pero que desafortunadamente poco o nada se ha repetido desde entonces.

Tomando lo dicho como base, llegamos a un elemento central para comprender el sentido profundo de la acción colectiva y el trasfondo de las metas de los lesionados. Axel Honneth (2009) construyó una teoría en la cual uno de los puntos medulares es que todos los seres humanos, en el fondo, buscamos constantemente el reconocimiento intersubjetivo. Así, las llamadas luchas por el reconocimiento refieren a «la pretensión recíproca de los individuos de que se les reconozca su identidad» (Honneth, 2009, p. 199). Trasladada ésta a la arena de la acción colectiva, los conflictos entre actores pueden referirse a impulsos morales que están por encima de la conservación individual o el razonamiento instrumental. En otras palabras, los lesionados no son «maximizadores 
de utilidad aislados» (Latorre, 2005:45), sino más bien individuos que, fundiéndose en lo colectivo, se ven guiados por normas morales en la persecución y obtención de reconocimiento. Una necesaria lucha en contra de la insensibilidad e indiferencia de las instituciones que devela una forma estructural de desprecio social (Honneth, 2009, p. 263) y que como tal no se limita al Estado. En efecto, para Honneth la búsqueda del reconocimiento implica tres formas positivas: 1) el amor-amistad; 2) el derecho y; 3) la solidaridad. El primero consiste en un reconocimiento en el nivel de las familias, los amigos, las parejas etc. El segundo en el nivel del Estado que implica, como lo hemos analizado para el caso de los lesionados, en la aceptación de la responsabilidad política y, por lo tanto, en la instrumentación de acciones públicas encaminadas a resolver sus demandas.

Sin embargo, el tercer nivel refiere al sentido de pertenencia a una comunidad de valores compartidos y que, como tal, no sólo debería sancionar las injusticias sino también sentirlas y/o luchar contra ellas con empatía y benevolencia. Lo anterior porque el reconocimiento intersubjetivo refiere a un efecto espejo (el yo se reconoce en el otro y viceversa), por lo que el gesto de aprobación sobre el otro es igualmente gesto de aprobación sobre el yo. De esta manera, los lesionados luchan por su reconocimiento dentro de una sociedad que tiende con mucha facilidad al olvido, que pretende no recordar lo que ocurrió el 22 de abril de 1992. Legitimando y profundizando con ello la condición estructural de desprecio social que niega la visibilización del otro. En este caso de los lesionados que, bajo esta perspectiva, se convierten en lesionados morales (Sauerwald, 2008, p. 49) a quienes se les ha negado la participación en una historia que pertenece a todos los mexicanos y a todos jaliscienses, como portadores de la herida abierta, de la laceración moral que aun sangra. Una invisibilización que, en ese efecto espejo, nos niega a nosotros mismos y a nuestra condición de sociedad.

\section{Breves conclusiones}

En este artículo hemos intentado demostrar que un análisis más denso de la complejidad social de las emociones, requiere de una reintroducción del cuerpo a las explicaciones sociológicas. Para el caso aquí desarrollado, lo anterior representó un acercamiento más profundo al daño sufrido por los lesionados de una tragedia en la cual las instituciones del Estado siguen desempeñando un papel central vía la indiferencia, la insensibilidad y la coerción. Por ello, las explosiones del 22 de Abril y sus latentes consecuencias humanas, son una pequeña muestra de las tantas heridas abiertas en México (y en Latinoamérica) que día con día nos apelan como sociedad. Lesiones morales que muchas veces no encuentran reparación o consuelo en nuestras instituciones disfuncionales, pero sí en la movilización social y/o en la integración y descarga de emociones morales dentro de tramas colectivas e identitarias.

En otra índole, estimamos que nuestra mayor colaboración a los debates teórico-conceptuales sobre las emociones, radica en la vinculación hecha entre éste campo fértil de la antropología y la sociología, las discusiones filosófico-político-sociológicas sobre conceptos tan significativos como lo son la justicia y la moral y una estructura de más amplio alcance como lo es la teoría del reconocimiento. Así, nuestro esfuerzo tiene que ver, en un plano más amplio, con una mejor comprensión del dolor humano en tanto campo legítimo y crucial, aunque muy abandonado, dentro de las ciencias sociales.

Finalmente, consideramos importante cerrar con una nota epistemológica-metodológica en términos de nuestro entendimiento y acercamiento a los sujetos sociales con los cuales construimos, en simultaneidad, nuestros objetos de estudio. Somos de la opinión que la mejor manera de penetrar en las emociones de los individuos es experimentándolas y compartiéndolas con ellos, pues sólo así, mediante la vivencia directa, podremos ser capaces de explicarlas en su complejidad sociológica y de debatirlas seria y profundamente a partir de estructuras teóricas más densas y reforzadas empíricamente. Además estimamos que como investigadores debemos establecer un compromiso con las causas sociales, pero en especial con aquellas que personifican las luchas por el reconocimiento de las minorías. Lo anterior, porque las ciencias sociales conllevan, desde nuestra perspectiva, una innegable responsabilidad de aportar al alivio de las desigualdades estructurales, de las invisibilizaciones de la vida moderna y de los agravios morales. 


\section{Bibliografía}

Bendelow, G, y Williams, S. (1998). Emotions, pain and gender. En G. Bendelow y S. Williams (eds.). Emotions in Social Life: Critical Themes and Contemporary Issues, (pp. 249-264). Londres, Inglaterra: Routledge.

(1995). Trascending the dualisms: toward a sociology of pain. Sociology of Health \& Ilness, 17 (2), 139165. Doi: https://doi.org/10.1111/j.1467-9566.1995.tb00479.x

Bericat, E. (2016). The sociology of emotions: four decades of progress. Current Sociology, 64 (3), 491-513. DOI: 10.1177/0011392115588355

Bourdin, G. (2016). Antropología de las emociones: conceptos y tendencias. Cuicuilco. Revista de Ciencias Antropológicas, (67), 55-74. Recuperado de http://www.redalyc.org/html/351/35149890004/

Breton, D. (2013). Por una antropología de las emociones. Revista Latinoamericana de Estudios sobre Cuerpos, Emociones y Sociedad, (10), 69-79. Recuperado de http://www.relaces.com.ar/index.php/relaces/article/ viewFile/208/145

Collins, R. (2001). Social movements and the focus of emotional attention. En J. Goodwin, J. Jasper y F. Polleta (eds.). Passionate Politics (pp. 27-44). Chicago, Estados Unidos: University of Chicago Press.

Eufracio, J. (2017). Testimonios sobre una herida abierta. Ecos y voces a 25 años de las explosiones del 22 de abril de 1992 en Guadalajara. Guadalajara, México: Miguel Ángel Porrúa y El Colegio de Jalisco.

Francis, L. (2007). Emotions and Health. En J. Stets y J. Turner (Eds.), Handbook of the sociology of emotions (pp. 591-610). Nueva York, Estados Unidos: Springer.

Gamson, W. (1992). Talking politics. Nueva York, Estados Unidos: Cambridge University Press.

González, E. (2006). Sobre el concepto de represión. Hispania Nova, revista de historia contemporánea, (6), 1-30. Recuperado de http://hispanianova.rediris.es/6/dossier/6d022.pdf

Gravante, T. y Poma, A. (2018). Manejo emocional y acción colectiva: las emociones en la arena de la lucha política. Estudios Sociológicos, XXXVI (108), 595-618. Doi: 10.24201/es.2018v36n108.1612

Gusfield, J. (2014). La cultura de los problemas públicos. El mito del conductor alcoholizado versus la sociedad inocente. Buenos Aires, Argentina: Siglo XXI Editores.

Hochschild, A. (1979). Emotion work, feeling rules, and social structure. The American Journey of Sociology, 85 (3), 551-575. Recuperado de https://www.jstor.org/stable/2778583

Honneth, A. (2009). Crítica del agravio moral. Patologías de la sociedad contemporánea. Buenos Aires, Argentina: FCE.

Jacobo F. (2016). Miradas antropológicas y sociológicas de las emociones. El análisis de la envidia en el pueblo nahua de Cuetzalan, Puebla. En M. Ariza (coord.). Emociones, afectos y sociología: diálogos desde la investigación social y la interdisciplina (pp. 373-395). Ciudad de México, México: UNAM.

Jasper, J. (2013). Las emociones y los movimientos sociales: veinte años de teoría e investigación. Revista Latinoamericana de Estudios sobre Cuerpos, Emociones y Sociedad, 4 (10), 46-66. Recuperado de https:// www.redalyc.org/articulo.oa?id=273224904005

(1998). The Emotion of Protest: Affective and Reactive Emotions in and around Social Movements. Sociological Forum, 13 (3), 397-424. Recuperado de https://www.jstor.org/stable/ 
684696?seq=1\#page_scan_tab_contents

Kemper, T. (2007). Power and Status and the Power-Status Theory of Emotions. En J. Stets y J. Turner (Eds.), Handbook of the sociology of emotions (pp. 87-113). Nueva York, Estados Unidos: Springer.

King, D. (2006). Activists and Emotional Reflexivity: Toward Touraine’s Subject as Social Movement. Sociology, 40 (5), 873-891. Recuperado de https://www.jstor.org/stable/42858246

Lalive, C. (2008). La vida cotidiana: construcción de un concepto sociológico y antropológico. Sociedad Hoy, (14), 9-31. Recuperado de https://www.redalyc.org/pdf/902/90215158002.pdf

Latorre, M. (2005). Los movimientos sociales más allá del giro cultural: apuntes sobre la recuperación de las emociones. Política y sociedad, 42 (2), 37-48. Recuperado de http://revistas.ucm.es/index.php/POSO/article/ view/POSO0505230037A

Leavitt, J. (1996). Meaning and Feeling in the Anthropology of Emotions. American Ethnologist, 23 (3), 514-539. Recuperado de https://www.researchgate.net/publication/ 227611920_Meaning_and_Feeling_in_the_Anthropology_of_Emotions

Moore, B. (1989). La injusticia: bases sociales de la obediencia y la rebelión. Ciudad de México, México: UNAM.

Polleta, F. y Jasper J. (2001). Collective Identity and Social Movements. Annual Review of Sociology, 27, $283-305$. Recuperado de http://faculty.sites.uci.edu/polletta/files/2011/03/2001-Polletta-and-Jasper-CollectiveIdentity.pdf

Poma, A. y Gravante, T. (2017). Emociones, protesta y acción colectiva: estado del arte y avances. Aposta, revista de ciencias sociales, (74), 32-62. Recuperado de http://www.redalyc.org/articulo.oa?id=495954961003

Reger, J. (2004). Organizational «Emotion Work» Through Consciousness-Raising: An Analysis of a Feminist Organization. Qualitative Sociology, 27 (2), 205-222. Doi: 10.1023/B:QUAS.0000020693.93609.6c

Romanos, E. (2011). Emociones, identidad y represión: el activismo anarquista durante el franquismo. Reis, revista española de investigaciones sociológicas, (134), 87-106. Doi:10.5477/cis/reis.134.87

Sauerwald, G. (2008). Reconocimiento y liberación: Axel Honneth y el pensamiento latinoamericano. Berlín, Alemania: Lit Verlag.

Scribano, A. y Artese, M. (2012). Emociones y acciones colectivas: un bosquejo preliminar de su situación hoy. En Cervio, A (comp.). Las tramas del sentir. Ensayos desde una sociología de los cuerpos y las emociones (pp. 85-114). Buenos Aires, Argentina: Estudios Sociológicos Editora. 